\title{
LA MUERTE RETRATADA: NINFAS ACUÁTICAS Y BELLAS DURMIENTES EN LA PINTURA VICTORIANA
}

\section{PORTRAITED DEATH: AQUATIC NYMPHS AND SLEEPING FINE IN VICTORIAN PAINTING}

\author{
Rocío Soto Delgado \\ (Universidad de Málaga, España) \\ mariarociosoto@hotmail.com
}

Recibido: 25 febrero 2020 Aceptado: 17 marzo 2020

\begin{abstract}
Resumen: En la Época victoriana se experimentó un paroxismo del culto a la muerte. En ese anhelo de dominar y contener la arbitrariedad de esta, el arte tuvo un papel indiscutible. Una atmósfera fúnebre pobló como un topos poético el universo estético victoriano y más especialmente el prerrafaelista. Tanto es así que una de las posturas adoptadas por la sociedad victoriana a la hora de representar la muerte consistió en la poetización e idealización del cadáver femenino, generalmente con una índole fetichista. Esta se efectuó a través de diferentes modos narrativos, poseyendo especial predicamento la muerte acuática y la muerte durmiente.
\end{abstract}

Palabras clave: Victorianismo; Prerrafaelismo; Muerte; Sacrificio; Agua; Sueño.

\begin{abstract}
In the Victorian era there was a paroxysm of the cult of death. In that desire to dominate and contain the arbitrariness of it, art played an important role. In the Victorian aesthetic universe and more especially the pre-Raphaelite, one of the positions when it comes to representing death consisted in the poetization and idealization of the female corpse, specifically with a fetishistic nature. This was carried out through different narrative modes: aquatic death and sleeping death.
\end{abstract}

Keywords: Victorian; Pre-Raphaelite; Death; Sacrifice; Water; Dream. 


\section{INTRODUCCIÓN}

En 1846, Edgar Allan Poe escribió "the death of a beautiful woman is, unquestionably, the most poetical topic in the world" en su ensayo The Philosophy of Compositionı. Para Poe, la tristeza y la melancolía se tornaban como los más legítimos tonos poéticos y en estos, la belleza encontraba la más alta de sus manifestaciones. De este modo, la muerte, el tema melancólico por excelencia, en conjunción con la hermosura femenina, expresaba de forma incuestionable el superlativo de sus principios básicos (Bronfen, 1992, p. 61). Ciertamente, esta sentencia no quedó exenta de ser el epicentro de una feroz controversia de la que la crítica contemporánea formó parte. Algunos críticos, que asumieron una coexistencia entre realidad y representación estética, acusaron a Poe de misoginia (Bassein, 1984)2. Por su parte, Bram Dijkstra exploró la forma en que aquellas peligrosas fantasías decimonónicas en las que la mujer, en un estado de enfermedad hasta la muerte, se alzó como un virtuoso icono de la feminidad y condescendió la creación de imágenes que constituyeron un paso más en la marginación de la mujer (Dijkstra, 1986, p. 24).

Sin embargo, lejos de ser una excéntrica reflexión por parte de Edgar Allan Poe, este inquietante y mordaz vínculo estético entre mujer y muerte se convirtió en una constante temática presente en la literatura (Madame Bovary, Anna Karenina o Naná) y en la pintura del siglo XIX. Es precisamente en este siglo cuando tiene lugar un exacerbado paroxismo del culto a la muerte (Doménech, 2010, p. 128). Hemos de considerar que, en la Era victoriana, esto es, el periodo de la historia de Inglaterra bajo el gobierno monárquico de la reina Victoria (1837-1901), la muerte fue considerada un evento social y la visualización del cadáver formaba parte del ritual de la vida familiar (Poulson, 1999, p. 192). Las ceremonias funerarias no eran sino formas de expresar un impulso común que la mayoría de culturas compartían, esto es, la necesidad de controlar la condición impredecible de la muerte biológica y evidenciar la victoria del orden sobre esta (Bloch \& Parry, 1982, p. 15)3. En ese anhelo de dominar y contener la arbitrariedad de la postrera, el arte también podía participar. De este modo, abandonarse

\footnotetext{
1 "La muerte de una mujer es, incuestionablemente, el tema más poético del mundo". 
a sí mismo a la emoción generada por un relato patético de la muerte o su representación en el lienzo, podía ser una experiencia catártica y tranquilizadora. Elizabeth Bronfen explica que sentimos deleite en las representaciones de la muerte porque acontecen en un entorno irreal. En la representación artística, se da una circunstancia que no se transfiere a la realidad, por lo que experimentamos la muerte desde una perspectiva de poder, reafirmándose así, nuestra falsa creencia de inmortalidad (Bronfen, 1992)4.

Contagiado de esta atmósfera fúnebre, el mundo de la necrofilia pobló como un topos poético el entorno artístico de la Época victoriana y, más concretamente, el universo estético prerrafaelita. La Hermandad Prerrafaelita fue fundada en el año 1848 por los pintores John Everett Millais, Dante Gabriel Rosetti y William Holman Hunt. Estos propugnaban el regreso al detallismo minucioso y al luminoso colorido de los primitivos italianos y flamencos, anteriores a Rafael y acudieron de modo recurrente a temas literarios, históricos y mitológicos como fuentes de inspiración. No obstante, en 1860 la Fraternidad abandonó sus principios formales y temáticos en aras de que cada artista prosiguiera su propio camino. Sin embargo, el movimiento tuvo su continuidad en aquello que denominamos posprerrafaelismo, caracterizado por el apego a los maestros del Renacimiento, el cultivo de temas literarios británicos y de la Antigüedad y la precisión decorativa (Museo Thyssen-Bornemisza, 2014, p. 11-15).

La postura adoptada por los artistas victorianos a la hora de representar la muerte consistió en la poetización e idealización del cadáver femenino, generalmente con una índole fetichista (Doménech, 2010, p. 128). Esta poetización se efectuó a través de diferentes modos narrativos, poseyendo especial predicamento dos: la muerte acuática y la muerte durmiente.

\section{LA MUERTE ACUÁTICA.}

En El agua y los sueños (1942), Gaston Bachelard escribió:

${ }_{4}$ Citado en Poulson, 1999, p.192. 
El agua es el elemento de la muerte joven y bella, de la muerte florecida y, en los dramas de la vida y de la literatura, es el elemento de la muerte sin orgullo ni venganza, del suicidio masoquista. El agua es el símbolo profundo, orgánico de la mujer que solo sabe llorar sus penas y cuyos ojos se "ahogan en lágrimas" con tanta facilidad... (Bachelard, 1994, p. 128).

En relación a esto, Julia Doménech arguye que la inmersión en el agua, elemento primitivo en el cual se origina la vida, simboliza el retorno a lo esencial: la muerte y, paradójicamente, el nacimiento (Doménech, 2010, p. 171). Esta idea de disolución acuática refleja un modo singular de entender el suicidio femenino, hecho absolutamente contemporáneo al hombre decimonónico. La licuefacción de estas doncellas heridas y abandonadas, es decir, el cambio de estado de sólido a líquido, es entendida no como una ruptura o un destino fatal, sino como la liberación de un cuerpo que encadena su existencia. Para alcanzar esta redención, estas heroínas eligen metamorfosearse deliberadamente en fluidos, atravesando el trance de morir en el agua, convirtiendo esta disolución en la solución perfecta para ellas (2010, p. 173). Tanto es así que incluso estas doncellas deslizadas por el agua, colmadas de voluntariedad y autoafirmación, son personificaciones de personajes míticos clásicos. La figura de las náyades, ninfas acuáticas por antonomasia, ocultas tras ropajes medievales o victorianos, se esconden tras numerosas imágenes prerrafaelistas y victorianas. En el libro quinto de Las Metamorfosis, Ovidio narra dos célebres fábulas acerca de ninfas que se convierten en fluidos, la de Ciane y la de Aretusa. Las lágrimas de Ciane, quien solloza al ver que Plutón vilipendia sus aguas sagradas, la ahogan, como escribió Bachelard, "con tanta facilidad" que acaban por convertirla en agua. Aretusa, por su lado, huyendo del obsesivo amor que Alfeo le profesaba y que ponía en peligro su virginidad, implora a la diosa Diana que la convierta en fuente, metamorfosis provocada por su propio sudor. A través de este parangón, queda evidenciado cómo el carácter simbólico del agua, transmisor de una transformación voluntaria, posee un carácter atemporal y clásico, puesto que también ofrece una válvula de escape a la coyuntura personal de nuestras heroínas decimonónicas (2010, p. 181).

Ofelia, personaje ficticio de Hamlet de William Shakespeare, se erigió como la heroína acuática por antonomasia y como leitmotiv del universo pictórico victoriano. Los 
prerrafaelistas fueron los primeros en hacerla musa de sus pinturas, no obstante, fue John Everet Millais quien contribuyó a crear los principales detalles pictóricos de su iconografía en 1851 [1].

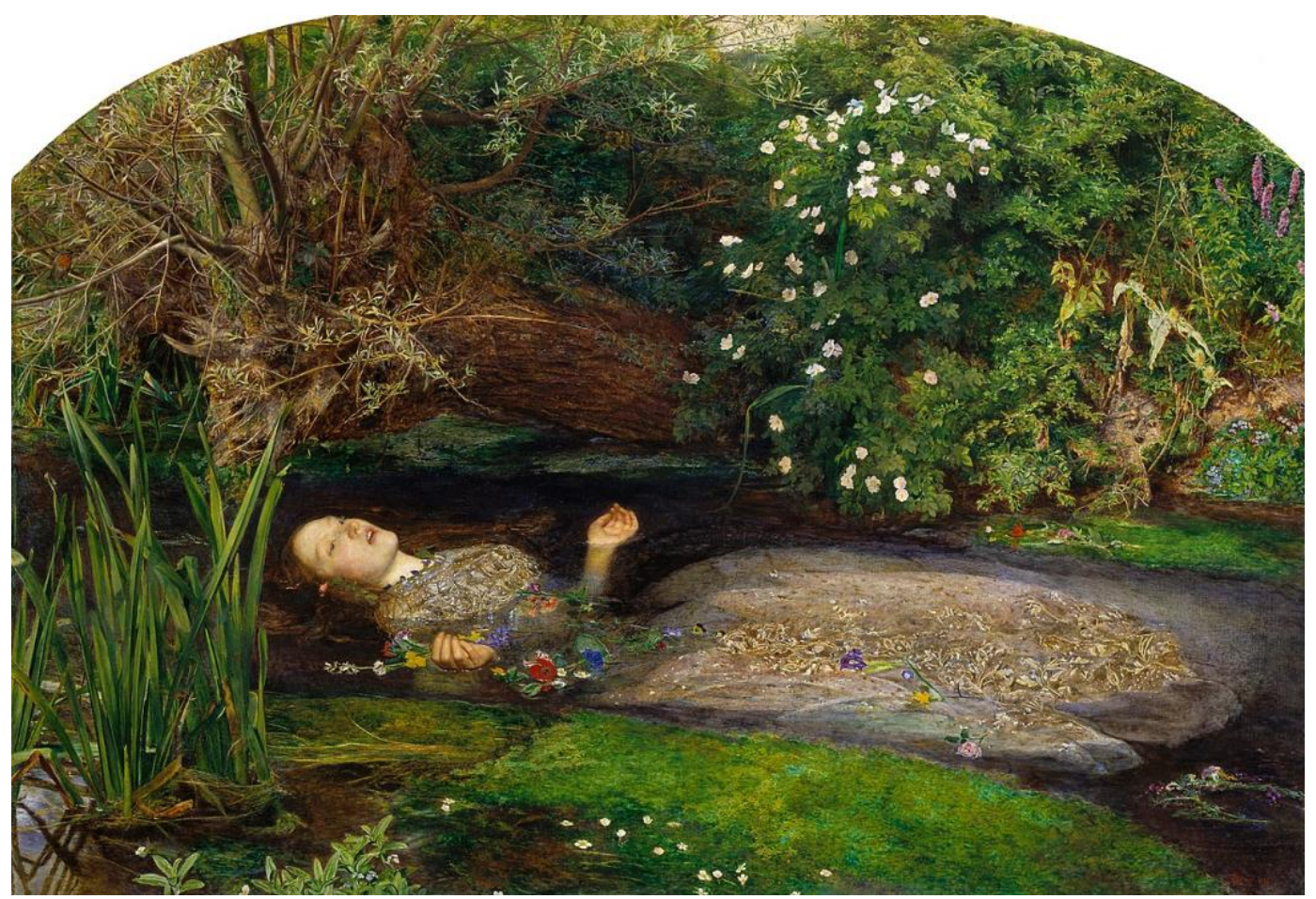

1. John Everett Millais, Ofelia, 1851-1852, Tate Gallery, Londres

El cuerpo de Ofelia, a excepción de manos y rostro, se disuelve paulatinamente en el agua, la cual está cubierta de plantas y flores pintadas con una gran fidelidad botánica y cargadas de simbolismo. El sauce, las ortigas y las margaritas simbolizan respectivamente el amor desamparado, la pena y la inocencia y están tomadas del propio texto de Shakespeare, mientras que los pensamientos pueden significar «amor en vano», y las violetas, se asocian con la desgracia, aunque también pueden significar castidad y la muerte de un joven (Aznar, 1990, p. 344). La apertura de las manos vislumbra una actitud de entrega al suicidio hídrico. El rostro, ensimismado y enajenado y con la boca entreabierta nos perturba. No ha fallecido, pero tampoco está viva. La heroína de Shakespeare posee una naturaleza transitoria a la licuefacción, evidenciando de modo enardecedor la transformación acuática relatada por Ovidio (Doménech, 2010, p. 80). 
La imagen del "cadáver" flotante de Ofelia permeó en el imaginario artístico decimonónico aplicándose a otras narraciones relacionadas con el gusto por el martirio femenino. En La mártir cristiana de Paul Delaroche [2], la santa, bautizada como la “Ofelia cristiana”, flota en el río Tíber con las manos atadas, enfatizando su absoluto desamparo. Otros artistas como Federico Faruffini adaptaron en la Virgen del Nilo [3], el tema a la moda en boga de falso orientalismo histórico. Combinando el tema de Ofelia con el de la crucifixión femenina, mostraba a su virgen con los pechos descubiertos flotando corriente abajo, estirada boca arriba sobre una cruz y rodeada de flores.

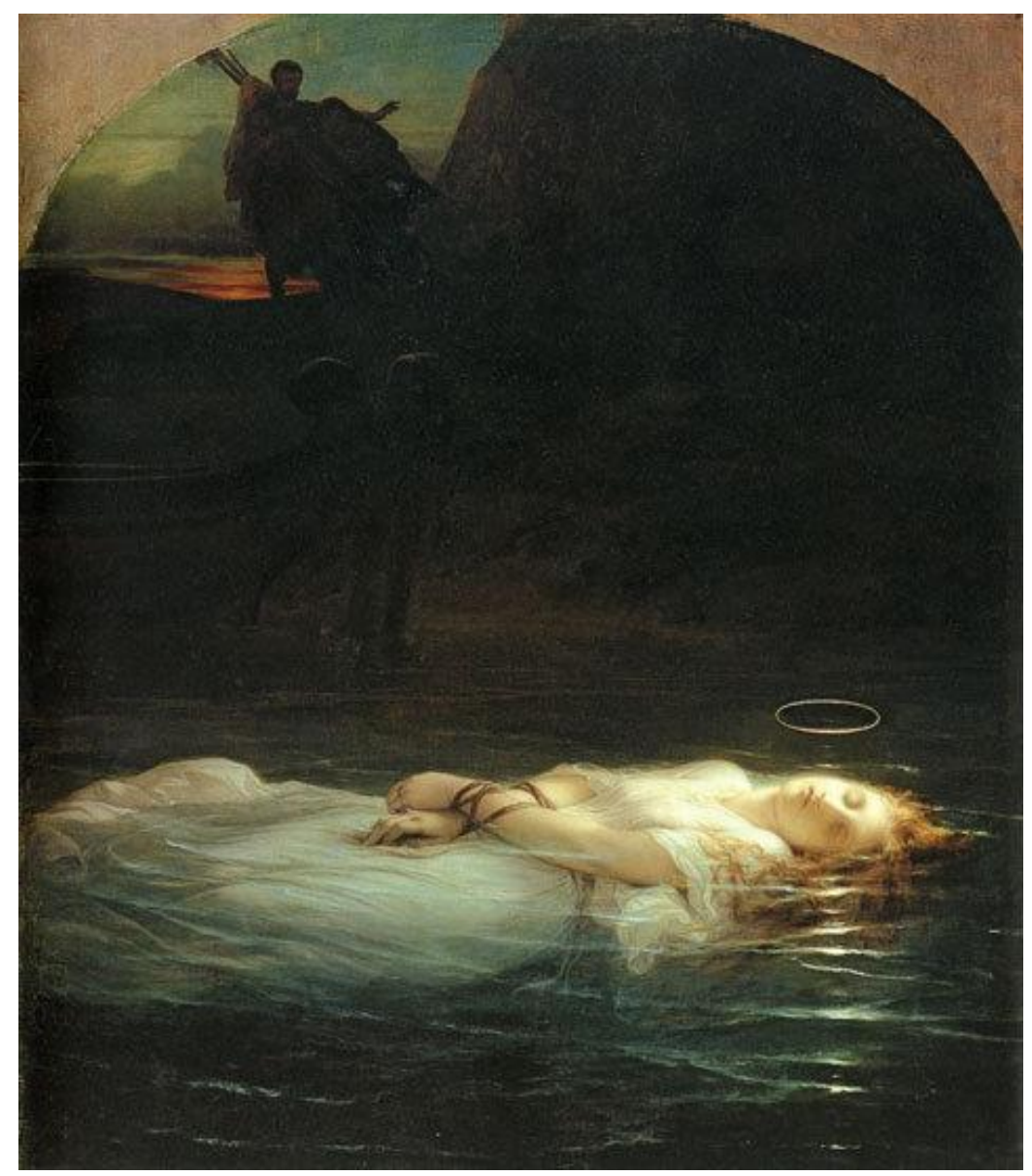

2. Paul Delaroche, Mártir cristiana ahogada en el Tíber en tiempos de Diocleciano, 1853, Museo del Hermitage, San Petersburgo. 


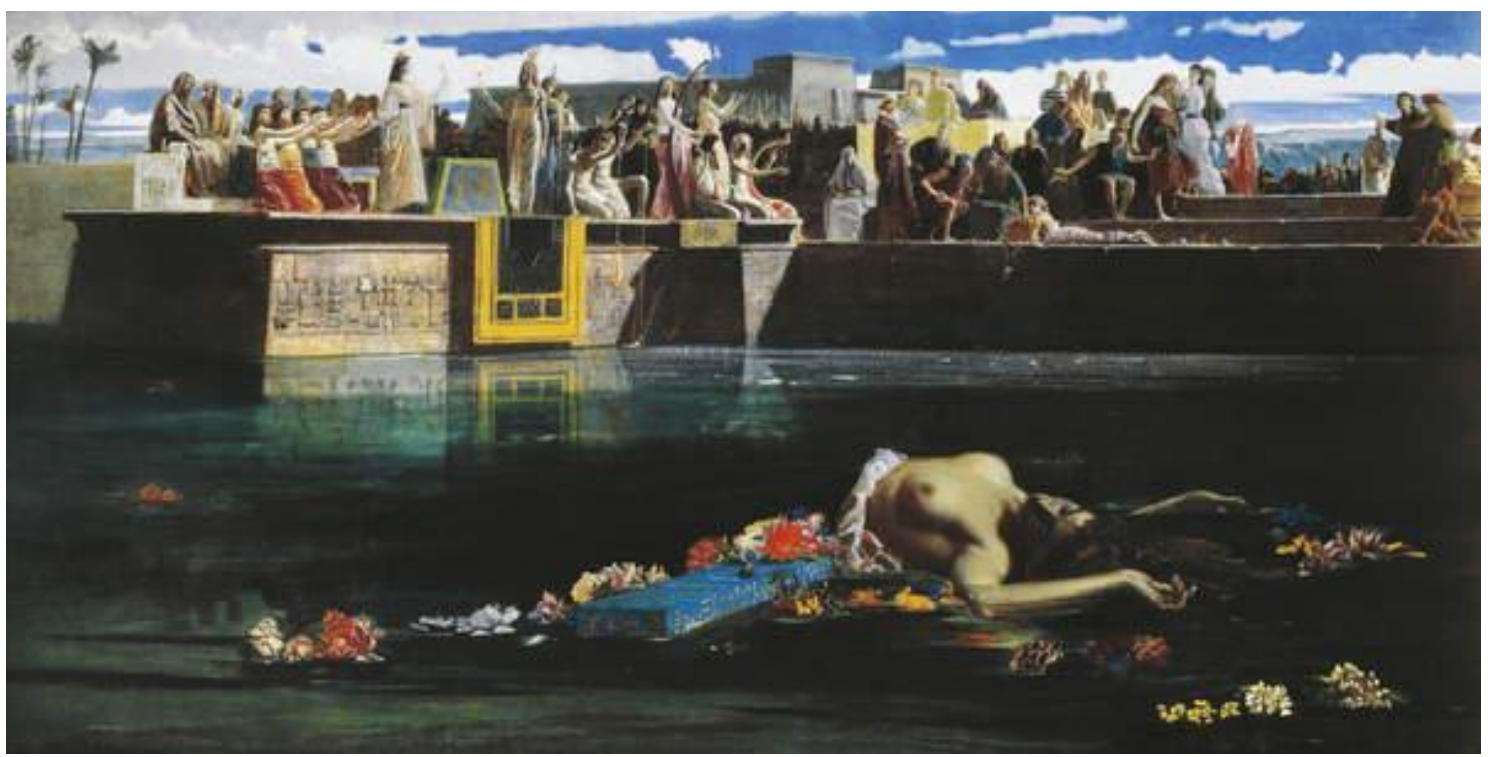

3. Federico Faruffini, El sacrificio de una virgen al Nilo, 1865, Galería Nacional de Arte Moderno, Roma.

\section{LA MUERTE DURMIENTE}

Decía Gaston Bachelard: «Es el agua soñada en la vida habitual, el agua del estanque que se "ofeliza" por sí sola, que se cubre con toda naturalidad de seres durmientes, de seres que se abandonan y que flotan, de seres que mueren dulcemente. Entonces, en la muerte, parece, que los ahogados flotantes siguen soñando...»(Bachelard, 1994, p. 129). Esta reflexión nos lleva a abordar otro modo narrativo en virtud del cual se expresa la muerte femenina, el sueño. La ecuación sueño-muerte de una mujer, de alto voltaje erótico, se erigía como un símbolo de obediencia y sumisión femenina, creándose una coyuntura ilusoria ideal en la que el hombre decimonónico podía ejercer el poder sobre la mujer sin restricción alguna.

El famoso poeta victoriano Alfred Tennyson (1809-1892) concibió un personaje que encarnó a la perfección este carácter pasivo y apasionado del autosacrificio durmiente a la par que acuático y que inspiró a los principales exponentes del universo estético prerrafaelita: Elaine de Astolat. Esta es la protagonista del poema "Lancelot y Elaine" (originalmente titulado "Elaine"), el cual formó parte de la que podemos considerar la obra más ambiciosa del autor, Idilios del Rey (Idylls of the King), publicada en 1859, de temática artúrica. El poema narra la historia de Elaine, "the lily maid of Astolat", y su obsesivo y no correspondido amor por Sir Lancelot, quien mantiene una relación adúltera 
con Ginebra, esposa de Arturo. El rechazo del caballero sume a Elaine en una gran tristeza que le confiere la muerte. Antes de morir, la dama deja instrucciones a su familia acerca de cómo debía ser tratado su cuerpo sin vida: debía ser depositado en una barca abandonada en el río y portar un lirio en una mano y una carta, destinada a Sir Lancelot, en la otra. Al llegar a la corte, el cadáver es descubierto por Arturo, Ginebra y Lanzarote, quien, sintiéndose responsable del trágico final de Elaine, organiza un fastuoso funeral en su honor. La muerte de Elaine constituyó el tema más reproducido y la representación de la "doncella victoriana de la muerte" se hizo popular y posibilitaba a los artistas recrearse en la belleza inmaculada de Elaine, descrita minuciosamente por Tennyson.

Debido a la propia naturaleza del relato de Tennyson, es interesante observar cómo la muerte acuática y la muerte durmiente se funden y se confuden en composiciones como las de T.E Rosenthal o la de Sophie Gengembre Anderson. [4][5] No obstante, otras como la de Edward Henry Corbould ya comienzan a otorgar protagonismo exclusivo al estado de sopor de la protagonista femenina. [6]

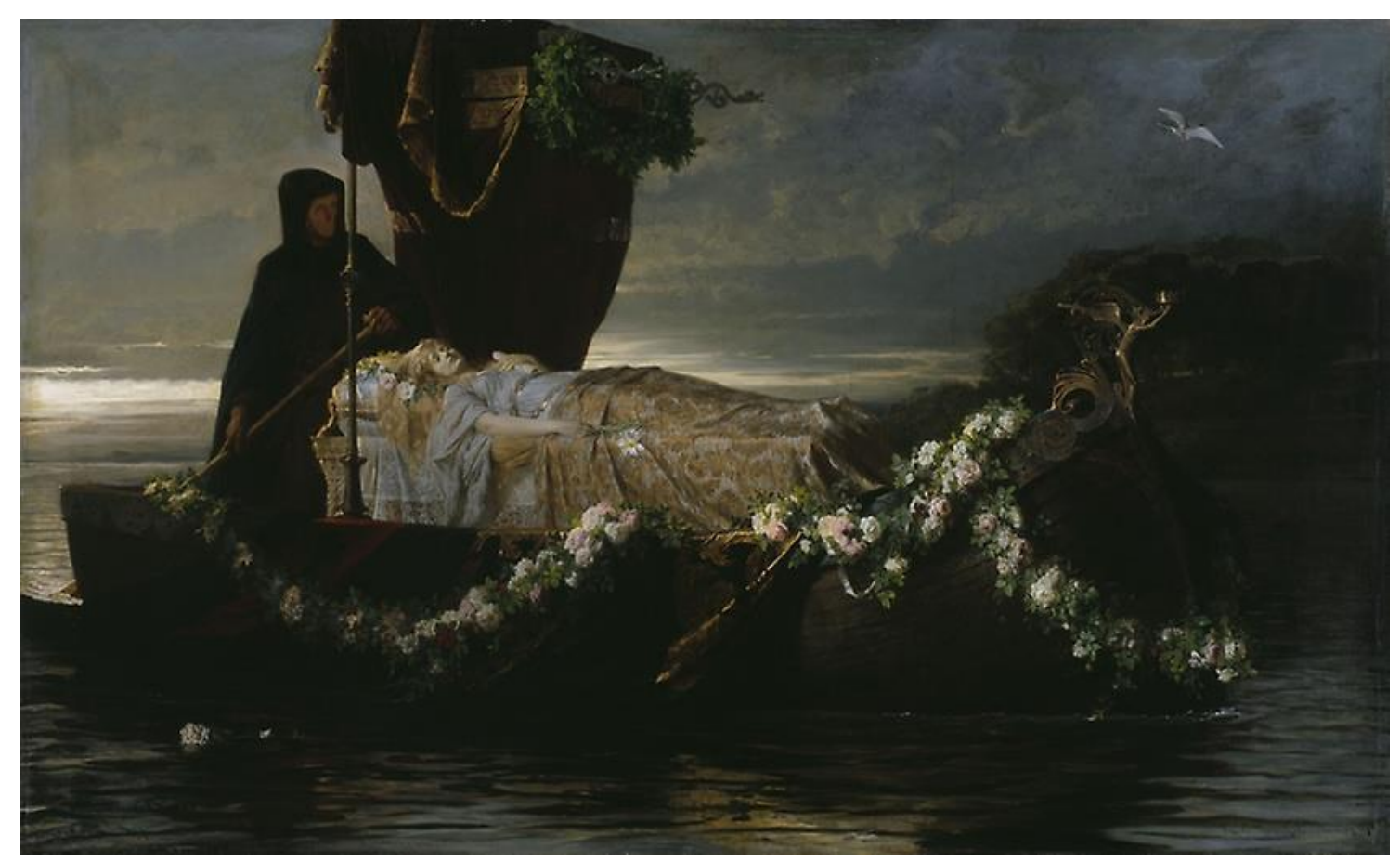

4. T. E. Rosenthal, Elaine, 1874, Chicago, Art Institute of Chicago 


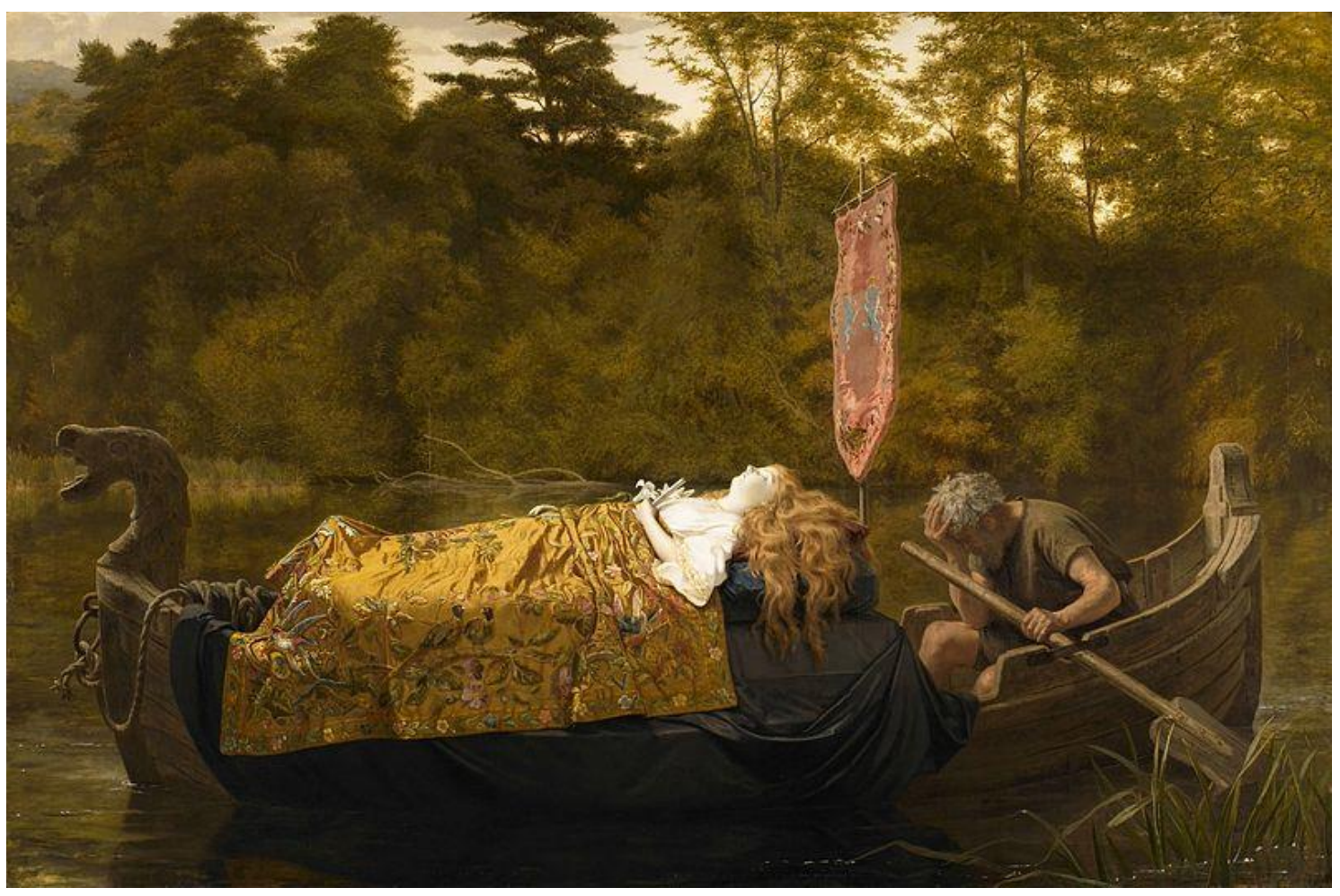

5. Sophie Gengembre Anderson, Elaine, 1870, Walker Art Gallery, Liverpool, Inglaterra

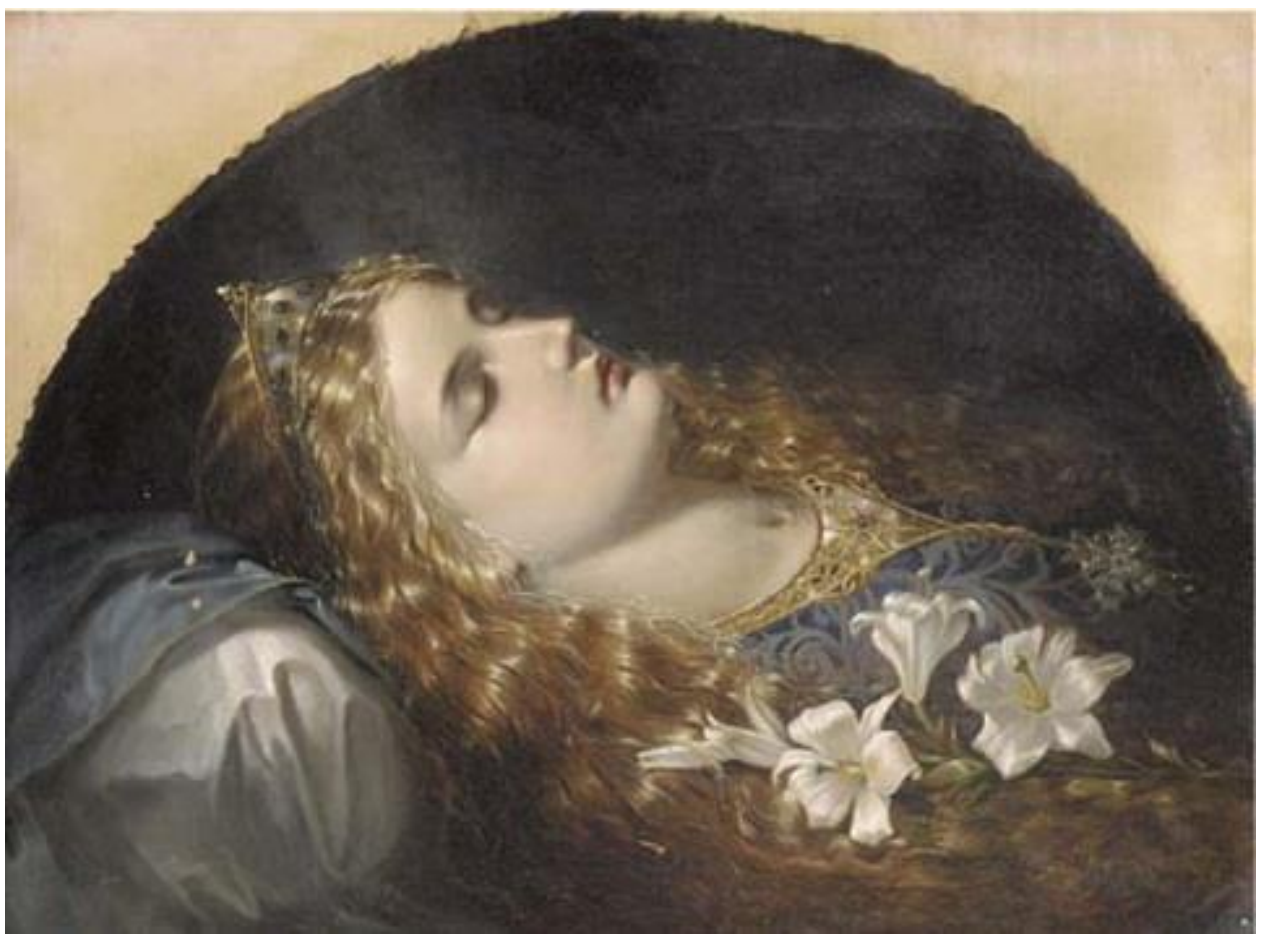

6. Atribuido a Edward Henry Corbould, Elaine, the lily maid of Astolat, 1863 
En cualquier caso, un canon de representación que entronca directamente con la tradición de heroínas dormidas en un sueño que se confunde con la muerte, tan propio del gusto victoriano (Dómenech, 2010, p. 223).

Es altamente significativa la descripción que el poeta hace sobre el cadáver de la fallecida Elaine cuando es situada en la barca para emprender su viaje hacia Camelot. Tennyson nos dice que "no parecía muerta / sino profundamente dormida, y yaciendo sonreía”. Es también sintomático el hecho de que ella misma pida que la envíen en un lecho. Se pensaba que una virgen debía estar inmersa en un sueño de inocencia perenne hasta que apareciese un caballero y la despertara con un beso, en aras de que esta cumpliese la misión para la que había sido desvelada, esto es, el matrimonio. De este modo, si una virgen fallecía antes de que su virginidad hubiese sido debidamente empleada, pasaba meramente del sueño de la inocencia al sueño de la muerte (Dijkstra, 1994, p. 61). El cuento de hadas de Blancanieves así como el de La bella durmiente pasaron a ser vistos como símbolos de la mujer en su virginal estado de sopor, de muerte en vida. En ambas, el cuerpo muerto o dormido se dispone como un objeto artístico para la contemplación (Doménech, 2010, p. 153). Dice Elizabeth Bronfen que el acto de ver significa posesión y placer y el acto de embalsamar a una mujer hermosa conlleva su idealización, ocultando de esta manera la posibilidad de deterioro (Bronfen, 1996, p. 100). La fascinación, dice esta misma autora, de estos cuerpos o fetiches, está condicionada por la tradición cristiana, viendo la veneración de la incorruptibilidad matérica de santos y mártires una excepción a esta traslación de la carne en un signo (Doménech, 2010, p. 153). Sigmund Freud definía este hecho a través del término escopofilia. Este expone que ver conduce a una apropiación física; que es preparatorio para la actividad sexual de tocar el otro cuerpo (Freud, 1905, p. 123245)5. En este caso, ver funciona como una forma de contacto. El cuerpo embalsamado se satisface como un objeto de la vista, sancionando la muerte, lo que de otra manera sería, para Freud, una perversión. El privilegio exclusivo de la mirada tal como se hace, suplanta y excluye la actividad sexual relacionada con tocar al otro (Bronfen, 1996, p. 102). Tanto Blancanieves como el resto de bellas durmientes encarnan, de esta manera, la apoteosis de una de las posiciones centrales atribuidas a la mujer en la cultura

${ }_{5}$ Citado en Bronfen, 1992, p. 102. 
occidental: el cuerpo femenino entregado está destinado a confirmar el poder de la mirada masculina (1996, p. 102).

Como ya se ha adelantado, el sueño hecho muerte y la muerte hecha sueño se convirtió en una fuente de deleite inagotable para pintores a finales del XIX. El modo de representación iconográfica de una bella mujer muerta también sirvió para pintar a mujeres durmientes, existiendo concomitancias entre ambos casos. Por ejemplo, George W. Joy, en su Juana de Arco expuesta en la Royal Academy en 1895 [7], pintaba a esta heroína, asociada innegablemente con una vida activa y con la batalla, experimentando el sueño de la inocencia femenina y de una aparente muerte momentánea(Dijkstra, 1994, p. 62). A modo de Venus, escondida bajo unos pliegues translúcidos, dormida e inerte es como Frederic Leighton retrató a Dorothy Dene en una de sus obras maestras, Sol ardiente de Junio, dando lugar a una composición cargada de erotismo y posibilidades escópicas. [8]

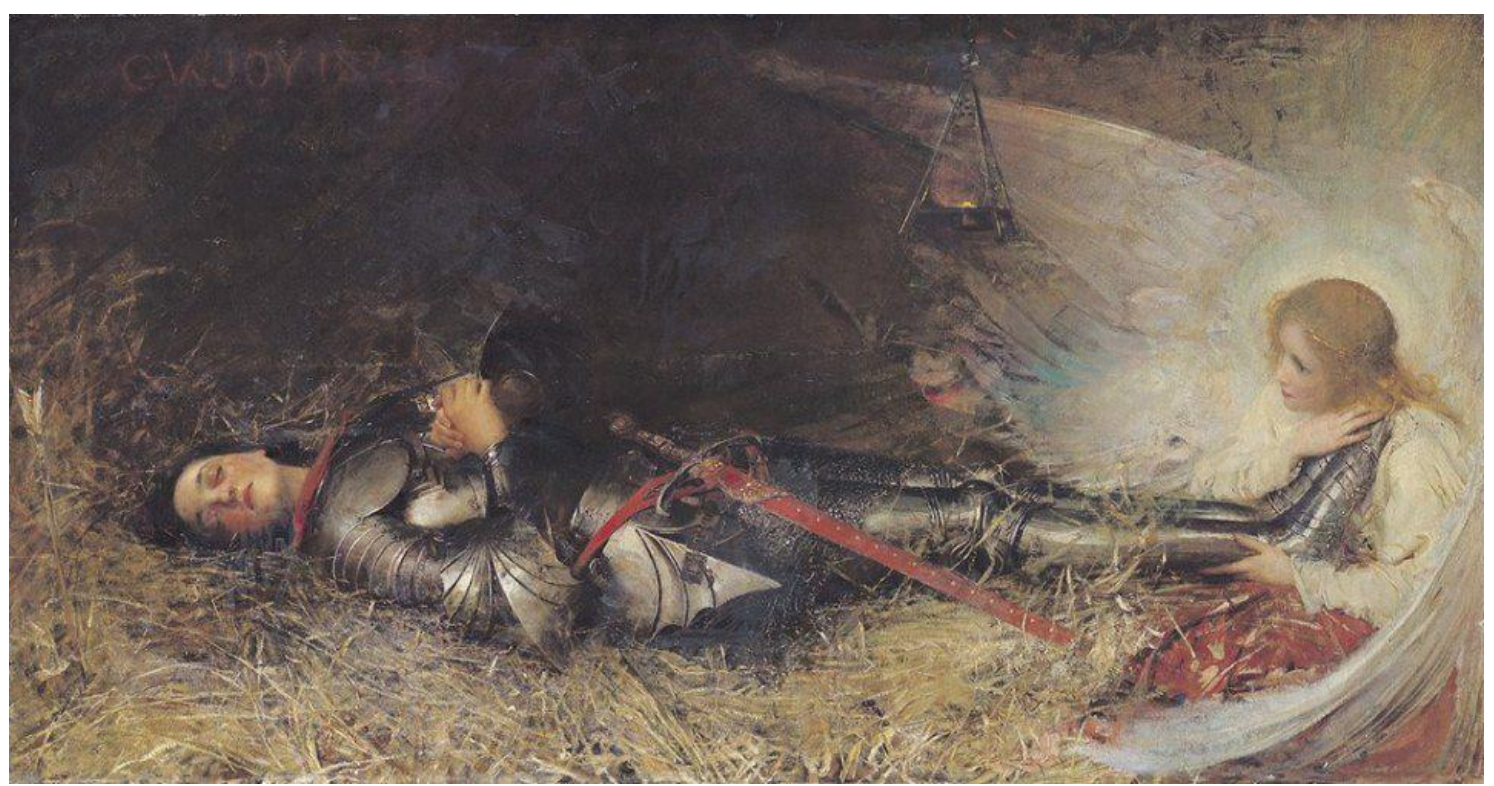

7. George W. Joy, Juana de Arco, 1895 


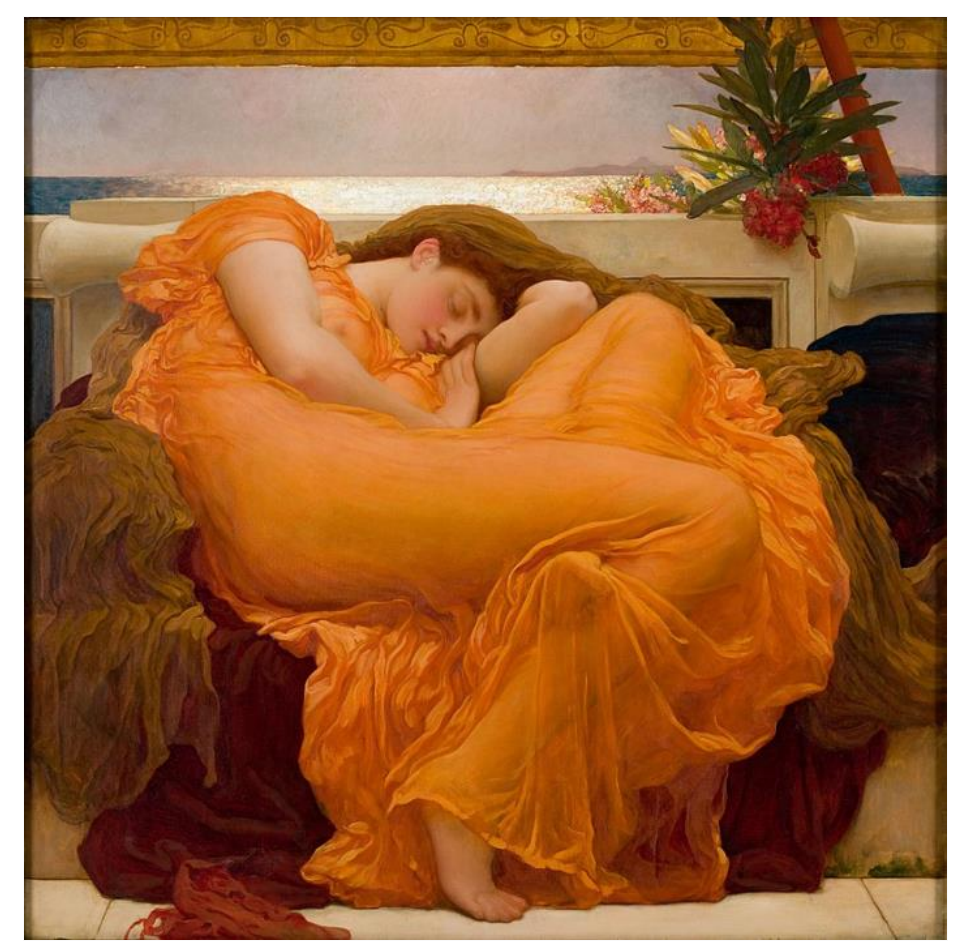

8. Frederic Leighton, Sol ardiente de Junio, 1895, Museo de Arte de Ponce, Ponce, Puerto Rico

Es interesante destacar que, una vez finalizada la época victoriana, el binomio mujer-sueño siguió poseyendo cierto predicamento en obras como la del pintor y escritor británico John Collier, quien ya en el siglo XX eligió como protagonista a La Bella Durmiente para uno de sus lienzos y que, en última instancia, nos evoca aquellas composiciones de Elaine de Astolat. [9]

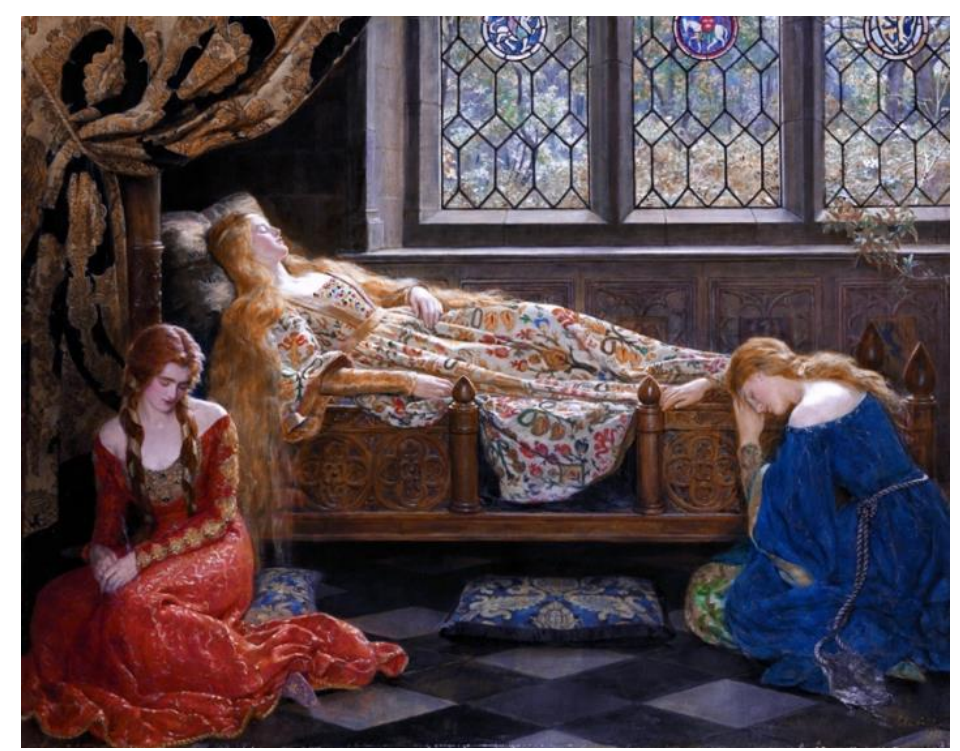

9. John Collier, The Sleeping Beauty, 1921 


\section{CONCLUSIONES}

Como hemos visto, independientemente de la excusa narrativa, la representación de mujeres bellas, muertas o dormidas, continuó siendo durante el siglo XIX uno de los modos predilectos por parte de los artistas en virtud del cual se evidenciaba el valor espiritual del sacrificio femenino pasivo. En ocasiones, ambos destinos, el acuático y el durmiente, se funden y se unifican. En otros, se desarrollan con total independencia e idiosincrasia. Lo que sí está claro es que, en su tránsito a la muerte, estas mujeres se despojan de su locura incipiente, de su "mal d'amour" o de toda su naturaleza terrenal para metamorfosearse en figuras de dimensiones heroicas. Las protagonistas muertas de los lienzos se convirtieron, como hemos visto, en retratos de famosas heroínas sacrificiales de la literatura, la historia y la mitología clásica, incluso cuando se tornaba evidente que el objeto fundamental de atracción de los artistas era, como Edgar Allan Poe escribió, «la muerte de una mujer bella» y el objetivo, la contemplación de un cuerpo inerte, pasivo e, irremediablemente, inofensivo (Dijkstra, 1994, p. 50).

\section{REFERENCIAS BIBLIOGRÁFICAS}

Aznar Almazán, Sagrario (1990), "Pintura prerrafaelita, en el límite de la modernidad", Espacio, Tiempo y Forma, Serie VII, Historia del Arte, t. 3, pp. 333-348.

Bachelard, Gaston (1978). El agua y los sueños: ensayo sobre la imaginación de la materia. Fondo de Cultura Económica: México.

Bronfen, Elisabeth (1992). Over her dead body: death, feminity and the aesthetic. Manchester University Press: Manchester.

Dijkstra, Bram, y Campos, Vicente (1994). Ídolos de perversidad: la imagen de la mujer en la cultura de fin de siglo. Debate: Madrid.

Doménech, Julia (2010). La belleza pétrea y la belleza líquida. El sujeto femenino en la poesía y las artes victorianas. Fundamentos: Madrid.

Museo Nacional Thyssen-Bornemisza (2014), Alma-Tadema y la pintura victoriana en la Colección Pérez Simón, pp. 11-15. Recuperado de: http://pdigital.museothyssen.org/index.html?revista=109073129\&pagina=14126 
Poulson, Christine (1999). The Quest for the Grail: Arthurian legend in British Art, 1840- 1920. Manchester University Press: Manchester. 